\title{
INGLÊS PARA QUÊ (M)? POLÍTICAS DE INTERNACIONALIZAÇÃO, SEUS PERCURSOS E AS PRÁTICAS DE SALA DE AULA DO PROGRAMA PARANÁ FALA INGLÊS
}

English For Wh(om)at? Internationalization Policies and their Paths in the Classroom Practices in "Paraná Speaks English" Program

\section{Adriana Cristina Sambugaro de MATTOS BRAHIM (UFPR) ${ }^{1}$ Gabriel Jean SANCHES (UNESPAR) ${ }^{2}$}

\begin{abstract}
RESUMO: Este trabalho tem como objetivo discutir as problematizações do pôster intitulado "Inglês para quê (m)? Políticas de internacionalização e seus percursos", apresentado no Fórum Internacional de Cultura, Literatura e Linguística Aplicada (FICLLA), realizado em 2018. Baseando-nos em alguns dos resultados da pesquisa de Sanches (2019) que versou sobre experiências vividas no Programa Paraná Fala Inglês (PFI) como ação de internacionalização de uma universidade estadual do Paraná, discutimos alguns conceitos teóricos que nortearam a proposição de práticas voltadas às necessidades de formação em língua inglesa dos participantes do PFI e que levaram a entendimentos sobre o papel do professor nessas práticas. A partir do estabelecimento do conceito de internacionalização como "espaço de democratização de conhecimentos", nossas reflexões trazem subsídios para pensarmos em como a agência docente se fez presente e foi determinante para a proposição de tentativas de práticas mais adequadas, contingentes e situadas para a obtenção de resultados mais coerentes em relação aos objetivos de um curso de língua inglesa como ação de internacionalização.
\end{abstract}

PALAVRAS-CHAVE: letramentos; internacionalização; ensino-aprendizagem de língua inglesa; concepção de língua.

ABSTRACT: This paper aims to discuss the problematizations in the poster "English for wh(om)at? Internationalization Policies and their Paths", presented during the International Forum of Culture, Literature and Applied Linguistics, in 2018. Inspired by some of the results from the research by Sanches (2019), which was about experiences in the Paraná Speaks English Program (PSE), as an internationalization action in a state university in Paraná, we discuss some theoretical concepts that supported some practical propositions for the goals in English language education and that lead to some meanings about the teacher's

\footnotetext{
${ }^{1}$ Professora no Setor de Educação Profissional e Tecnológica (SEPT) e no Programa de Pós-Graduação em Letras na Universidade Federal do Paraná (UFPR). Doutora em Linguística Aplicada pela Universidade de Campinas (UNICAMP). adrianacsmbrahim@gmail.com

2 Professor na Universidade Estadual do Paraná (UNESPAR). Mestre em Estudos Linguísticos pela Universidade Federal do Paraná (UFPR). hampshirelocks@ @otmail.com
} 
role in those educational practices. From the concept of internationalization as a space for "knowledge democratization", our reflections bring supported ideas for us to think about how the teacher's agency was there and also how it was important to the proposal of more adequate, contingent and situated educational practices, which can bring better results in terms of an English language course as an internationalization action.

KEYWORDS: literacies; internationalization; English teaching and learning; language conception.

\section{INTRODUÇÃO: POR QUE A IMAGEM DO LIQUIDIFICADOR?}

O "Fórum Internacional de Cultura, Literatura e Linguística Aplicada: práticas e transgressões", evento em homenagem ao Professor Dr. Lynn Mario Trindade Menezes de Souza (USP), teve como objetivo "construir espaços dinâmicos e dialógicos ao longo de todo o evento, como uma forma de proporcionar a todos e todas a oportunidade de contribuir para a discussão dos assuntos abordados, bem como aproximar opiniões 'leigas' de "especializadas"”. Assim, as modalidades de apresentações de trabalhos foram diferentes daquelas que normalmente acontecem em eventos como este, ou seja, o FICLLA foi organizado com Rodas de Conversa e Apresentação de Pôsteres.

Diante disso, resolvemos submeter uma proposta de pôster em formato diferente, explorando possibilidades imagéticas. Assim, tivemos a ideia de trabalhar com a imagem de um liquidificador e, dentro dele, imagens e frases que, de um lado representassem alguns programas, como o PFI e, de outro, alguns conceitos e perspectivas teóricas sobre língua e ensino de línguas que estavam sendo lidas e discutidas por nós para a definição do referencial teórico mais adequado e que pudesse embasar o projeto de pesquisa sobre práticas de sala de aula do PFI que estávamos delineando.

Além disso, pensamos em incluir alguns símbolos que representassem recursos didáticos disponibilizados pela internet, uma vez que havia de nossa parte o interesse em também investigar o material didático online disponibilizado para as aulas de inglês, por meio da plataforma Smart English. Pois bem, mas quem faria o desenho, a imagem? E, mais concretamente, qual a relação da ação de "misturar ingredientes", característica de um liquidificador, que tínhamos em mente para a imagem, e principalmente para propor 
problematizações sobre práticas de sala de aula do PFI e práticas do PFI como ação de internacionalização?

Aos poucos, em diálogo com colegas, as duas questões foram resolvidas. A primeira, por meio de uma indicação de uma colega desenhista para a elaboração da imagem. A segunda, com diálogo e negociações entre nós, autores deste trabalho, a partir de várias conversas que foram, aos poucos, delineando as ideias que gostaríamos de discutir na apresentação do pôster.

A seguir apresentamos o pôster com a imagem do "liquidificador da Internacionalização" - desenho belíssimo desenvolvido exclusivamente para o pôster por uma colega, Letícia Pilger, professora de língua portuguesa e aluna do mesmo programa de pós-graduação em Letras ao qual estamos vinculados. E, em seguida, apresentamos algumas ideias que nos ajudaram a compor as problematizações do pôster. 
Dossiê Especial FICLLA

REVISTA X, Curitiba, volume 14, n.5,p. 181-202, 2019

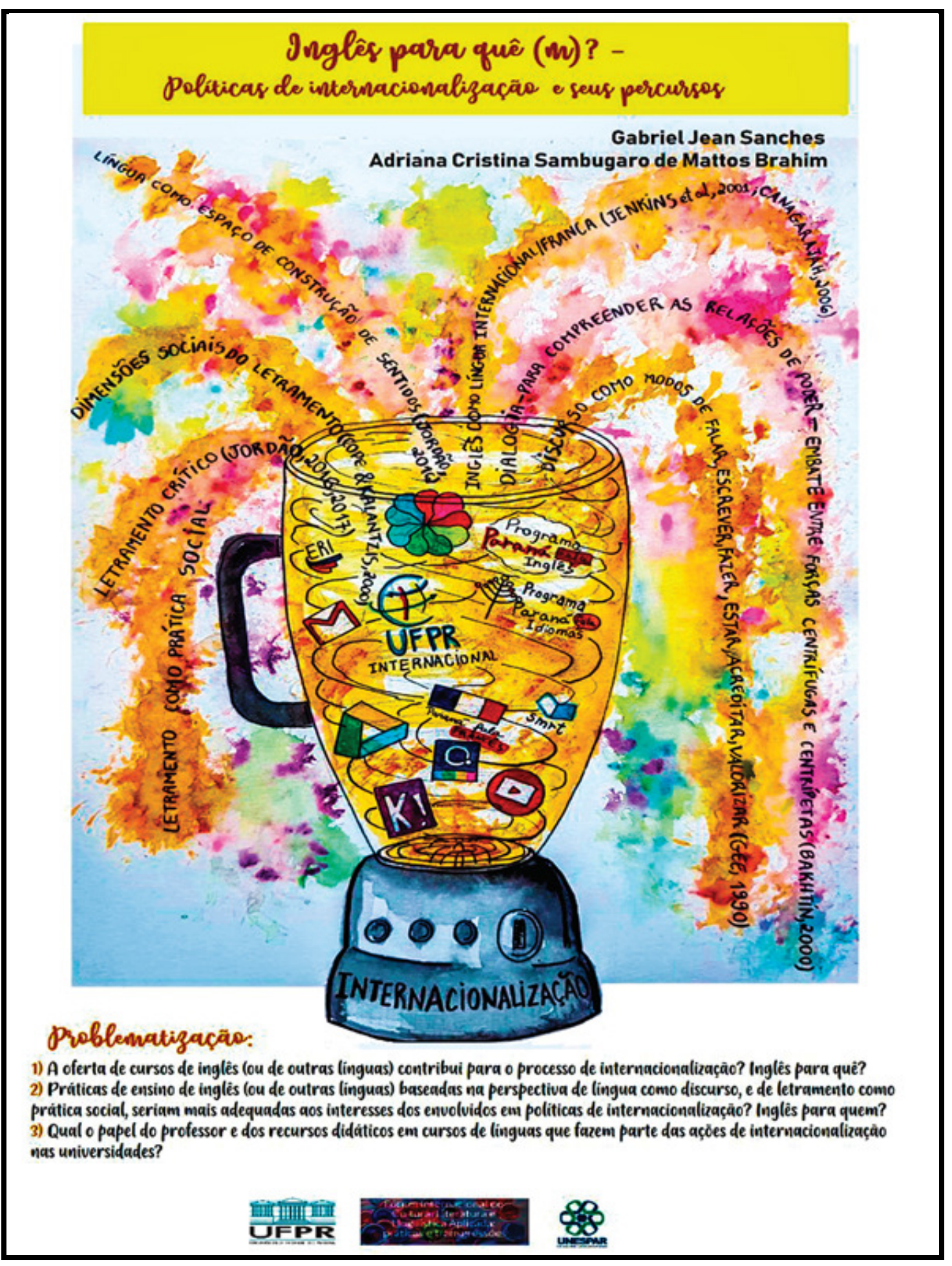

Fonte: Pôster apresentado no FICLLA-UFPR (2018).

Imagem de Letícia PILGER, elaborada exclusivamente para a composição do pôster. 
A imagem acima teve como objetivo, a partir da apresentação das ideias iniciais trazidas anteriormente nesta introdução, refletir sobre o fato de que, quando tentamos adequar perspectivas teóricas, e principalmente nossos entendimentos sobre elas, "misturadas" às nossas práticas de sala de aula, não podemos prever o resultado.

Um dos sentidos que construímos, é que esta mistura pode ser bastante interessante, podendo resultar em uma deliciosa vitamina, em algo que nos beneficie, que nos dê prazer, que nos satisfaça, trazendo bem estar, ou seja, contribuindo para práticas de sala de aula que levem a resultados satisfatórios, positivos. No entanto, sabemos que nem sempre será assim. A nossa intenção com a imagem do liquidificador "misturando" perspectivas, conceitos, foi fazer uma analogia, no sentido de afirmar que "misturas" como esta podem conter, sem que percebamos, um ou mais ingredientes que as faça transbordar, tanto no sentido positivo, quanto no negativo.

Nos parece, no entanto, que o transbordamento traz mais um sentido negativo, pois se os ingredientes transbordarem no processo de liquidificação, sujam o entorno onde o liquidificador está. Em outras palavras, a sujeira provocada nos traz uma ideia negativa na medida em que limpar toda a sujeira do transbordamento dos ingredientes não é uma tarefa prazerosa que alguém queira realizar, mesmo sendo necessária.

Além disso, pode haver desperdício de ingredientes e de tempo, que também são aspectos negativos. Desta forma, o sentido que intencionamos levar para o pôster foi o de que o transbordamento da mistura de concepções, teorias, práticas pedagógicas e recursos didáticos em ações de internacionalização pode ser negativo se as práticas forem definidas e realizadas sem uma análise cuidadosa dos "ingredientes" que serão misturados. Outra ideia presente é o cuidado que precisamos ter em relação à velocidade que usaremos para a ação de liquidificar esses "ingredientes". Se a velocidade for baixa, cuidadosa, pode nos ajudar a também evitar o transbordamento.

A partir das breves explicações analógicas que fizemos nesta introdução, queremos afirmar que os aspectos relacionados e constitutivos dos percursos das políticas de internacionalização, como ações educativas, devem ser pensados cuidadosamente, com aprofundamento teórico e metodológico. Além disso, acreditamos ser importante promover 
discussão e diálogo sobre os objetivos, interesses e motivações dos partícipes dessas ações, para a definição cautelosa de objetivos viáveis a serem alcançados.

Por fim, queremos crer que as reflexões presentes neste texto, fomentadas pelas problematizações que acompanharam a imagem do pôster apresentado no FICLLA, possam reverter em um "transbordamento positivo" - de informações, de percepções, de construções de sentido (MONTE MÓR, 2018) sobre os dados gerados e análises realizadas em pesquisa supracitada (vide SANCHES, 2019) - ou seja, que possam resultar, por hora, em uma boa vitamina!

\section{PROBLEMATIZAÇÃO 1: A OFERTA DE CURSOS DE INGLÊS (OU DE OUTRAS LÍNGUAS) CONTRIBUI PARA O PROCESSO DE INTERNACIONALIZAÇÃO? INGLÊS PARA QUÊ?}

\section{O Ciência sem fronteiras (CSF), o Idiomas sem fronteiras (ISF), o Paraná Fala Inglês (PFI) e a Internacionalização}

Nesta seção apresentaremos brevemente alguns programas que fazem parte de ações de internacionalização de universidades públicas brasileiras, contemplando principalmente seus objetivos para fomentar reflexão sobre a problematização 1 .

Antes de fazermos esta apresentação, queremos nos posicionar em relação ao conceito de internacionalização ao qual nos filiamos. Para isso, trazemos o trabalho de Ono e Gomes (2018), no qual os autores apresentam a seguinte conceitualização:

\footnotetext{
Por internacionalização, entendemos que seja um processo de mão dupla, com ações locais que reverberem em outras ações e que contribuam para o desenvolvimento de cidadãos conscientes de que vivemos em um mundo onde a troca de saberes e experiências não pode se limitar apenas ao contexto em que vivemos (ONO; GOMES, 2018, p.76).
}

Concordamos, assim, que ações de internacionalização não podem se limitar, por exemplo, à oferta de testes de proficiência, como proposto inicialmente pelos programas, cujos objetivos apresentaremos no decorrer desta seção. Ou seja, ações de internacionalização, como a oferta de momentos de prática ou de cursos de língua inglesa (como os do PFI), devem não somente "oferecer um ambiente livre e democrático" (ONO; GOMES, 2018, p. 80) para a prática de línguas, mas sim dever se constituir de verdadeiros 
espaços de democratização de conhecimentos e, assim, fomentar o verdadeiro propósito da internacionalização das universidades que está relacionado "à cooperação acadêmica, solidariedade institucional e liberdade de pensamento" (DIAS SOBRINHO, 2010 apud SANTOS; GUIMARÃES-IOSIF, 2013, p. 15).

Os programas Ciência sem fronteiras (CSF), Idiomas sem fronteira (ISF), e o programa Paraná Fala Inglês (PFI) fazem parte de iniciativas da esfera de políticas públicas, voltadas para o ensino de línguas nas universidades com papel importante no processo de internacionalização, pois constituem ações com o objetivo de capacitar os estudantes a interagirem em contextos de internacionalização (SANCHES, 2019, p. 02).

No site oficial do Ciência sem Fronteiras (CSF), constam as seguintes informações:

[O programa]... visa promover a consolidação, expansão e internacionalização da ciência e tecnologia, da inovação e da competitividade brasileira por meio do intercâmbio e da mobilidade internacional. A iniciativa é fruto de esforço conjunto dos Ministérios da Ciência, Tecnologia e Inovação (MCTI) e do Ministério da Educação (MEC), por meio de suas respectivas instituições de fomento - CNPq e Capes -, e Secretarias de Ensino Superior e de Ensino Tecnológico do MEC.

\section{$[\ldots]$}

[Os objetivos são:] 1. Investir na formação de pessoal altamente qualificado nas competências e habilidades necessárias para o avanço da sociedade do conhecimento; aumentar a presença de pesquisadores e estudantes de vários níveis em instituições de excelência no exterior; 2.Promover a inserção internacional das instituições brasileiras pela abertura de oportunidades semelhantes para cientistas e estudantes estrangeiros; ampliar o conhecimento inovador de pessoal das indústrias tecnológicas; atrair jovens talentos científicos e investigadores altamente qualificados para trabalhar no Brasil. (PORTAL CSF, 2011).

Consideramos importante destacar que, conforme discutido por Sanches (2019), de acordo com o Portal CSF (2011), as metas do programa "foram propostas inicialmente até 2015, prevendo a oferta de 101.000 bolsas a estudantes e pesquisadores no País e no exterior, das quais 75.000 seriam financiadas com recursos do Governo Federal e 26.000 concedidas com recursos da iniciativa privada" (id., ibid., p. 50). Dessa forma, as vagas seriam para o maior número de estudantes que desejassem ter acesso ao ensino de língua estrangeira e, ao mesmo tempo, que possibilitasse o desenvolvimento de relações com universidades de outros países em forma de parceria. 
O Inglês sem Fronteiras (ISF) - uma iniciativa do CSF - foi instituído em 2012 pelo Ministério da Educação. Um dos objetivos deste programa foi "propiciar a formação e capacitação de estudantes de graduação das instituições de educação superior para os exames linguísticos exigidos para o ingresso nas universidades anglófonas" (BRASIL, 2012, p. 28). Assim, observamos que o ISF foi uma iniciativa que objetivou capacitar os participantes do CSF que não possuíam proficiência linguística necessária para participar das atividades do programa, ou seja, "as ações empreendidas no âmbito do programa Inglês sem Fronteiras serão complementares às atividades do programa Ciência sem Fronteiras" (BRASIL, 2012, p. 1), conforme apresentado nos objetivos específicos:

[...] II - ampliar a participação e a mobilidade internacional de estudantes de
graduação das instituições de educação superior brasileiras, para o
desenvolvimento de projetos de pesquisa, estudos, treinamentos e capacitação em
instituições de excelência no exterior; III - contribuir para o processo de
internacionalização das instituições de educação superior e dos centros de
pesquisa brasileiros [...]. (BRASIL, 2012, p. 01 ).

A ampliação da mobilidade internacional, de acordo com os proponentes do CSF, seria viabilizada por meio de testes de proficiência linguística. No entanto, conforme apresentado por Sanches (2019, p. 51), as ações do ISF eram atividades complementares do CSF que se ampliaram com a inclusão de cursos de outras línguas estrangeiras - além da aplicação de testes de proficiência - para a capacitação de estudantes, de professores e agentes das instituições.

Estes aspectos de criação dos programas federais brevemente supracitados, possibilitou a implementação de programas de iniciativa estadual, como é o caso do Paraná Fala Inglês (PFI), um Programa destinado às Instituições Estaduais de Ensino Superior (IES), realizado em parceria com a Secretaria de Estado da Ciência, Tecnologia e Ensino Superior (SETI) e que faz parte de um Programa mais amplo chamado Paraná Fala Idiomas(PFI), que teve sua primeira fase entre 2014 e 2016.

Conforme apresentado na pesquisa de Sanches (ibid.), a segunda fase do PFI iniciou em junho de 2017 quando o Governo do Estado do Paraná firmou uma parceria com o Governo Canadense, representado pela Languages Canada e pela Smart English. Ambas são apresentadas respectivamente como "uma associação do setor de educação linguística 
do Canadá, e [...] instituição com exclusivo e inovador sistema de aprendizagem de LI desenvolvido pelo Departamento Pedagógico da Canadian College of English Language" (SETI, 2014 apud SANCHES, 2019, p. 52). Na segunda fase do programa, o intuito foi "ir além da preparação para os testes de proficiência" para se aproximar das "reais necessidades de apoio ao processo de internacionalização em todas as esferas da atividade universitária" (id., ibid.). Nesse sentido, encontramos no site do SETI (2014) a seguinte descrição: "serão ofertados cursos que viabilizem a utilização da língua inglesa em contexto real, a exemplo do inglês acadêmico e inglês para fins específicos" que "contribuirão para potencializar as publicações em revistas de alto impacto internacional", e também “oferecem a possibilidade de preparar a comunidade acadêmica para cooperações internacionais no contexto da pesquisa, do ensino e da extensão, a partir de um cenário de diversidade linguística e cultural" (id., ibid.).

Essas informações nos fazem pensar que, a partir de 2017, houve uma preocupação no sentido de que as práticas passassem a estar mais voltadas às ações de internacionalização que permitissem aos estudantes um maior contato com o contexto de pesquisa, ensino e extensão. Assim, a partir desta fase do programa os objetivos passaram a ser outros, ou seja, passaram a envolver contextos de "diversidade linguística e cultural para além dos preparatórios para testes de proficiência", o que nos parece ir mais ao encontro do sentido de internacionalização ao qual nos filiamos, ou seja, "espaço de democratização de conhecimentos", de "cooperação acadêmica, solidariedade institucional e liberdade de pensamento" (SETI, 2014).

Para atingir o objetivo de "ir além dos preparatórios para testes de proficiência" por meio dos cursos de inglês do PFI, foram disponibilizados computadores e acesso a um livro didático online, além de um coordenador pedagógico para apoiar a elaboração de planejamento em conjunto com os professores envolvidos. Mas computadores, um livro didático e um coordenador pedagógico seriam elementos suficientes para o desenvolvimento de uma proposta que envolva "contextos de diversidade linguística e cultural para além dos preparatórios para testes de proficiência? A resposta à esta pergunta fará parte das reflexões que trazemos na sequência das nossas discussões. 
Diante do que foi apresentado até aqui, o nosso entendimento é que a oferta de cursos de língua inglesa no PFI, como ação de internacionalização, responderia à problematização número 1 (Inglês para quê?), ou seja, inglês para fomentar publicações internacionais por meio de um trabalho que envolva "contextos de diversidade linguística e cultural", superando a ideia de que os preparatórios para os testes de proficiência dariam conta de preparar os envolvidos para "cooperações internacionais no contexto da pesquisa, do ensino e da extensão" (SETI, 2014).

O que nos parece bastante problemático é afirmar que essas possibilidades, ou seja, de utilização do inglês "para potencializar as publicações em revistas de alto impacto internacional" ou para "cooperações internacionais no contexto da pesquisa, do ensino e da extensão", ou ainda "criar espaços de democratização de conhecimentos" seja viabilizado por meio de cursos que se baseiam em um material didático, mais especificamente um livro online, com características de um trabalho de língua na perspectiva de código, ou como sistema abstrato, herdado do estruturalismo de Saussure, conforme discutido por Jordão: "um sistema fechado, transparente e passível de estudo quando abstraída de seu uso social e ideológico" (JORDÃO, 2006, p. 02). Esta é a concepção de língua identificada no material didático, conforme a pesquisa de Sanches (2019). O livro online é baseado em treino de tópicos gramaticais o que é limitador no sentido de não permitir atingir os objetivos do programa propostos para a segunda fase e, da mesma forma, para atingir os objetivos a partir da concepção de internacionalização defendida aqui. A partir dessas reflexões, questionamos: o que fazer com o material didático? Como os professores podem exercer a sua agência para atuarem sem este material didático, ou adaptá-lo, ressignificá-lo, em suas práticas de sala de aula? Como trabalhar na perspectiva da "diversidade linguística e cultural", de "democratização de conhecimentos"? Como seriam essas práticas? O que os proponentes entendem por "diversidade linguística e cultural”? Que concepção de língua seria pertinente e adequada para práticas pedagógicas que desenvolvam usos da língua em contextos de "diversidade linguística e cultural" (SETI, 2014) em atividades de internacionalização?

Esses são alguns questionamentos que fazemos, entre outros possíveis que poderíamos fazer, em relação à coerência entre o material didático utilizado e as práticas 
necessárias para atender às demandas de usos do inglês em ações de internacionalização, a partir dos objetivos do programa na implementação de sua segunda fase.

Na próxima problematização tentaremos discutir, brevemente, como pensamos que essas práticas poderiam ser viabilizadas no sentido de atingir minimamente os objetivos propostos para o PFI.

\section{PROBLEMATIZAÇÃO 2: PRÁTICAS DE ENSINO DE INGLÊS (OU DE OUTRAS LÍNGUAS) BASEADAS NA PERSPECTIVA DE LÍNGUA COMO DISCURSO, E DE LETRAMENTO COMO PRÁTICA SOCIAL, SERIAM MAIS ADEQUADAS AOS INTERESSES DOS ENVOLVIDOS EM POLÍTICAS DE INTERNACIONALIZAÇÃO? INGLÊS PARA QUEM?}

\section{Concepção de língua nas práticas de sala de aula do PFI}

Nosso objetivo nesta seção é discutir brevemente, a partir de nossos entendimentos, se as práticas de sala de aula no PFI, baseadas na perspectiva de língua como discurso (JORDÃO, 2006, 2007, 2016) e de letramento como prática social (STREET, 1995, 1997, 2012), seriam mais adequadas para se atender aos objetivos do PFI como ação de internacionalização, trazendo para a discussão, os atores fundamentais nesse cenário das práticas de sala de aula em cursos de língua inglesa do programa, ou seja, os alunos. Desse modo, retomando a pergunta - Inglês para quem? - trazemos à baila um aspecto que a pesquisa de Sanches (2019) evidenciou: a importância de se aliar os objetivos do PFI como ação de internacionalização aos objetivos e interesses de aprendizagem dos alunos participantes. Neste sentido, as práticas de sala de aula devem ser espaços para que eles possam se perceber como responsáveis por seus processos de aprendizagem e, principalmente, atribuidores de sentidos ou, como nas palavras de Fish (1980 apud JORDÃO, 2013):

[...] confrontando procedimentos interpretativos no espaço escolar, em um ambiente de colaboração, os alunos têm a oportunidade de perceber-se na posição de atribuidores de sentidos, de se ver como agentes construtores de significados em conjunto com comunidades discursivas de interpretação, como já nos alertavam as teorias de recepção nos anos 80. (id., ibid., p. 84). 
Assim, pensando em propostas para as práticas do PFI que propiciem um trabalho colaborativo, com espaço para a agência dos alunos, percebemos que é imprescindível levar em conta as necessidades e os interesses dos alunos que se matriculam nesses cursos. Mas como isso seria possível? Como seria possível criar espaços de agência dos alunos com o uso de um material didático cujo objetivo era somente o "treino" de tópicos de gramática? Esses questionamentos nos levam a pensar na necessidade de outras formas de trabalho com a língua. E assim aconteceu com as práticas propostas e analisadas por Sanches (2019) em sua pesquisa, conforme discutiremos em seguida.

Por meio da liberdade e flexibilidade propiciada pela coordenação pedagógica durante o planejamento dos cursos do PFI, na sua segunda fase, as práticas analisadas na pesquisa de Sanches (ibidem) não partiram somente do uso do livro didático online, mas também do uso de outras atividades e materiais que foram elaborados pelo professorpesquisador. A elaboração dessas atividades foi uma tentativa de planejamento a partir da concepção de língua como discurso, inspirado nos trabalhos de Jordão $(2006,2007,2016)$ e também nos trabalhos de Monte Mór $(2008,2013$, 2018) para o estabelecimento de práticas de usos de linguagem na perspectiva de práticas sociais (STREET, 1995, 1997, 2012). A concepção de língua como discurso e de letramento como prática social inserem-se nos estudos dos novos letramentos, mais especificamente dos letramentos críticos (MONTE MÓR, 2018) e podem apoiar teoricamente não somente o desenvolvimento de habilidades linguísticas específicas, mas sobretudo podem propiciar outros olhares, outras leituras de mundo, e assim, outras práticas de ensino-aprendizagem - além daquelas limitadas do livro didático online - baseadas numa perspectiva estruturalista saussuriana de linguagem. Foi esse um dos resultados apontados pela investigação de Sanches (2019).

Em outras palavras, houve a compreensão por parte do professor-pesquisador, de que as práticas de sala de aula do PFI não poderiam estar baseadas somente no livro didático, porque se assim fosse, não seria viável o estabelecimento de práticas condizentes com a perspectiva de língua como discurso (JORDÃO, 2006, 2007, 2016) e também não adequadas aos objetivos do programa. Desta forma, observamos que o professorpesquisador buscou desvincular-se do uso absoluto do livro didático online, na busca de um trabalho mais contextual e contingencial de usos da língua inglesa. 
O professor-pesquisador passou a elaborar atividades que levassem em conta as necessidades de usos da língua inglesa por parte dos alunos participantes do programa em atividades de internacionalização, partindo dos conhecimentos de língua inglesa que esses alunos já traziam para as aulas e, ao mesmo tempo, entendendo sua prática como temporária (contingencial), o que demanda reflexão e adaptação constantes a partir do que vai vivenciando, negociando e experienciando com seus alunos. Ou seja, queremos de forma geral afirmar que a prática pedagógica do professor não é simplesmente realizar o que é inicialmente proposto por um livro didático. É importante que o professor tenha uma "atitude agentiva" (HIBARINO, 2018) e a partir dela crie oportunidades para que os alunos se conscientizem de que é vivenciando situações, conhecendo e praticando diferentes formas de se expressar, oralmente ou por escrito, que eles podem se desenvolver no aprendizado de uma língua.

Dessa forma, acreditamos que o ensino-aprendizagem de línguas não deve estar pautado somente no estudo de regras gramaticais, mas sim em atividades planejadas pelo professor e que permitam ao aluno desenvolver conhecimentos em situações de uso contingente e situado da língua (JORDÃO, 2016), em diferentes necessidades de comunicação/interação. Esses usos exigem dos participantes habilidades que, no nosso entendimento, não são propiciadas por meio de práticas pedagógicas que se baseiam em exercícios de gramática, baseados numa visão de língua como código, mas numa visão de língua como discurso, baseada numa perspectiva pós-estruturalista, que traz várias implicações em relação aos processos de ensinar e aprender línguas. Na visão de língua como discurso, conforme afirma Jordão (2006),

\footnotetext{
a língua não é percebida como um código a ser decifrado, um emaranhado de pistas que devemos investigar. Ao invés de mediar nossas relações com o mundo, num mundo supostamente transparente e neutro, a língua constitui nosso mundo, e não apenas o nomeia. Ela constrói discursos, produz efeitos de sentido indissociáveis dos contextos em que se constituem (BAKHTIN, 2003). Conceber língua como discurso é perceber a língua como ideológica, perpassada por relações de poder que ela mesma constrói; é perceber as marcas de determinações culturais nos textos que produzimos; é perceber os gêneros discursivos como mecanismos de estabelecimento de sentidos possíveis. (id., ibid., p. 07).
}

Ainda buscando enfatizar um trabalho na perspectiva de língua como discurso nas práticas de sala de aula do PFI, trazemos as reflexões de Menezes de Souza (2011, p. 04), 
principalmente quando o autor afirma que os alunos já trazem seus conhecimentos e experiências de mundo para o processo de leitura, ou seja, toda e qualquer construção de sentido que um sujeito pode fazer, parte primeiramente de sua realidade social. O mesmo teórico afirma que autor e leitor estão no mundo, "são sujeitos sociais, cujos "eus" se destacaram e tiveram origem em coletividades sócio históricas de "não-eus".

Argumentamos que os alunos do PFI, como alunos de qualquer outro contexto educacional, possuem conhecimentos diversos que, se reconhecidos pelos professores e, de acordo com Freire (1996), respeitados, permitirão "estabelecer uma necessária 'intimidade' entre os saberes curriculares fundamentais aos alunos e a experiência social que eles têm como indivíduos" (id., ibid., p. 33-34), ou seja, a valorização dos diferentes conhecimentos dos alunos e a prática de relacioná-los àqueles do currículo educacional, pode contribuir para a construção de novos conhecimentos.

As práticas de sala de aula do PFI (no contexto pesquisado), planejadas na tentativa de se trabalhar com a perspectiva de língua como discurso, não só criaram um novo espaço para a construção de sentidos, como também permitiram que os alunos se relacionassem com os temas de cada aula, a partir da realidade deles, ou seja, a partir daquilo que poderia ser relevante a partir da visão de mundo de cada um.

Desta forma, as atividades permitiram a comunicação e a interação de forma mais adequada ao desenvolvimento de práticas sociais de usos da linguagem e à formação para a internacionalização, ou seja, os alunos aprenderam aspectos da língua inglesa por meio das trocas de conhecimentos dos temas propostos, a partir do reconhecimento do potencial e da realidade deles, trazendo a possibilidade de reflexão "como sujeitos no mundo" Menezes de Souza (2011), o que não está presente em práticas de ensino baseadas numa perspectiva estruturalista saussuriana de língua.

Assim, por meio da agência do professor no planejamento das atividades de ensino, houve o reconhecimento de aspectos sociais e culturais envolvidos o que confere um caráter humanista e discursivo para as práticas de sala de aula do PFI. Sobressai-se, então, a ideia de que essas tentativas foram coerentes também no sentido de aliar o ensino de língua inglesa à uma ação de internacionalização de uma universidade pública, colocando os alunos como protagonistas, como sujeitos agentes na construção de sentidos, sejam eles 
orais, escritos, visuais, auditivos. Essas práticas, queremos crer, também propiciou ressignificação do que é ensinar-aprender línguas para o professor-pesquisador e para os alunos envolvidos.

Portanto, a partir das discussões apresentadas aqui, podemos ousar afirmar que, a partir da problematização 2, "práticas de ensino de inglês, baseadas na perspectiva de língua como discurso e de letramento como prática social seriam mais adequadas aos interesses dos envolvidos em cursos de línguas como ações de internacionalização”.

\section{PROBLEMATIZAÇÃO 3: QUAL O PAPEL DO PROFESSOR E DOS RECURSOS DIDÁTICOS EM CURSOS DE LÍNGUAS QUE FAZEM PARTE DAS AÇÕES DE INTERNACIONALIZAÇÃO NAS UNIVERSIDADES?}

\section{O papel do professor: agência?}

Nesta seção sobre a problematização 3, apesar de citar o papel dos recursos didáticos, daremos enfoque ao papel do professor nas práticas de sala de aula do PFI, uma vez que já fizemos considerações sobre material didático na seção anterior. Além disso, a pesquisa de Sanches (2019) demonstrou que uma de suas hipóteses - sobre ser fundamental o papel dos recursos didáticos para as suas práticas no PFI - não foi confirmada, conforme discutiremos a seguir.

A hipótese de que o uso de ferramentas digitais propiciadas pelo livro didático online usado no PFI poderia proporcionar um espaço para a realização de atividades que envolvessem a multimodalidade e a partir daí outras possibilidades de construir sentidos, logo não foi confirmada. Ou seja, o fato de se tratar de uma material didático acessado por meio da internet, com a possibilidade de usos de alguns recursos de edição, por exemplo, não é garantia de uma prática pedagógica que considere não só a escrita, mas também outros meios de construir sentidos tais como gestos, expressões, imagens, vídeos, gifs, etc. Para que isso aconteça é preciso que o professor compreenda o seguinte: a sua prática de sala de aula necessita ser realizada a partir de uma visão menos compartimentada de linguagem, e que necessariamente não seja baseada no ensino de tópicos gramaticais.

Trazemos à discussão a perspectiva dos estudos dos novos letramentos (multiletramentos e letramentos críticos), justamente por criticarem a visão estruturalista 
saussuriana de linguagem - que estabelece um "ensino tradicional" de línguas. De acordo com Monte Mór (2012), uma proposta baseada nesta perspectiva tradicional,

\begin{abstract}
[...] remeteria ao tipo de trabalho pedagógico realizado nas escolas e universidades brasileiras, que, em grande parte, seguem uma orientação hermenêutica tradicional [...] e uma epistemologia convencional. Nesta, a construção do conhecimento tende a ocorrer de forma compartimentada, fragmentada em subáreas de conhecimento. Essa perspectiva leva os aprendizes a organizar os conhecimentos de forma não transdisciplinar, uma organização que dificulta o fluxo de conhecimentos, experiências ou vivências de um compartimento para outro. (MONTE MÓR, 2012, p. 178).
\end{abstract}

A partir destas afirmações da autora, no nosso entendimento, esta perspectiva (“tradicional”) não permite que o professor faça reflexões e elabore um planejamento que possibilite um maior engajamento por parte dos estudantes, num processo mais voltado para língua como discurso (JORDÃO, 2006, 2007, 2016). Assim, em nossas práticas e em nossas escolhas, durante o planejamento prévio e durante a prática, o desejo por mudança pode ser o que Jordão (2006, p. 01) chama de "entrecruzamento", em que o professor de línguas, ao ter contato com teorias que podem ajudá-lo a desenvolver uma prática diferente da esperada, numa perspectiva discursiva, faz com que suas escolhas sejam modificadas no momento de planejar suas aulas, tornando a reflexão um processo constante e indispensável para o estabelecimento de práticas mais coerentes e que atenda de forma mais qualitativa aos objetivos de suas práticas.

Ainda segundo a autora, neste processo de reflexão sobre suas próprias práticas, a agência do professor, suas escolhas e atitudes em sala de aula, são processos que fazem parte de uma construção social. Portanto, não há como negar o fato de que, ao entrarmos em sala de aula, há sempre uma concepção pautando nossa agência, e nem sempre nossas escolhas são baseadas no que é descrito por linguistas renomados. Ou seja, muitas vezes nos deparamos com algumas de nossas práticas que partiram de nossas escolhas, ao exercitarmos a nossa agência, e que fazem parte dos sentidos que construímos sobre o que devemos considerar ao planejarmos nossas aulas para um determinado grupo de alunos. Além disso, o nosso constante interesse e curiosidade em buscar alternativas mais viáveis em termos de melhores resultados de aprendizagem para nossos alunos, nos levam, como 
afirmado por Freire (1996), à nossa formação permanente e profissionalmente necessária. Neste sentido, para Freire

[...] o que há de pesquisador no professor não é uma qualidade ou uma forma de ser ou de atuar que se acrescente à de ensinar. Faz parte da natureza da prática docente a indagação, a busca, a pesquisa. O de que se precisa é que, em sua formação permanente, o professor se perceba e se assuma, porque professor, como pesquisador. (FREIRE, 1996, p. 32).

Concordamos com Freire quando o autor afirma ser relevante que os professores se percebam como pesquisadores e que co-construam reflexões sobre as suas práticas. Entendemos que este processo se dá por meio da agência docente que, no caso das práticas de sala de aula do PFI como ação de internacionalização, a agência do professorpesquisador foi de fundamental importância para o estabelecimento de práticas em sala de aula mais adequadas aos objetivos de ensino do PFI.

Encontramos uma reflexão interessante sobre agência docente no trabalho de Hibarino (2018), no qual a pesquisadora, em outro contexto de ensino-aprendizagem de língua inglesa, problematiza a concepção de agência docente. A pesquisadora entende agência docente "como processo vivenciado dialogicamente, que incorpora as experiências, os aspectos ideológicos e materiais e a influência do aspecto projetivo no campo práticoavaliativo dessas experiências" (id., ibid., p. 79).

Nas práticas analisadas na pesquisa de Sanches (2019), a agência docente foi a mola propulsora para a problematização de práticas baseadas em um material didático estruturalista, e para o desenvolvimento de práticas outras, baseadas numa visão não compartimentada de língua. Assim, acreditamos que a agência docente permite que o professor reflita sobre suas práticas, transforme-as, e ressignifique-as, pois, não sendo assim, há um engessamento do trabalho docente e a impossibilidade de um olhar amplo para lidar com as situações instáveis, heterogêneas e múltiplas (MENEZES DE SOUZA, 2011) presentes no mundo globalizado e refletidas na sala de aula de línguas.

Retomando a problematização 3, e a partir de nossas discussões nesta seção, acreditamos que os recursos didáticos não podem ter o papel central nas práticas de sala de aula do PFI. O papel central deve ser o do professor com os seus alunos, pois dependendo de suas possibilidades de agência, ele poderá promover, junto com seus alunos, práticas de 
ensino-aprendizagem de inglês mais coerentes, mais adequadas e que podem trazer melhores resultados em termos de preparo para atender aos objetivos de internacionalização das universidades.

\title{
CONSIDERAÇÕES SOBRE A "VITAMINA DA INTERNACIONALIZAÇÃO"
}

Em tempos de ameaças à Democracia no nosso país, o que dispensa explicações, nos inspiramos em Paulo Freire para iniciar a apresentação de algumas considerações que denominamos a "vitamina da internacionalização". Para Freire,

\begin{abstract}
O educador democrático não pode negar-se o dever de, na sua prática docente, reforçar a capacidade crítica do educando, sua curiosidade, sua insubmissão. Uma de suas tarefas primordiais é trabalhar com os educandos a rigorosidade metódica com que devem se "aproximar" dos objetos cognoscíveis. E esta rigorosidade metódica não tem nada que ver com o discurso "bancário" meramente transferidor do perfil do objeto ou do conteúdo. É exatamente neste sentido que ensinar não se esgota no "tratamento" do objeto ou do conteúdo, superficialmente feito, mas se alonga à produção das condições em que aprender criticamente é possível. E essas condições implicam ou exigem a presença de educadores e de educandos criadores, instigadores, inquietos, rigorosamente curiosos, humildes e persistentes. (FREIRE, 1996, p. 28-29).
\end{abstract}

Neste trecho da obra Pedagogia da Autonomia, o autor traz vários aspectos que caracterizam o perfil do "educador democrático": aquele que assume a sua prática docente com responsabilidade, comprometimento e ética, construindo um processo de aprendizagem crítico. No caso das práticas de sala de aula do PFI, as reflexões que tentamos construir neste trabalho, inspiradas nos dados analisados da pesquisa de Sanches (2019), foi possível identificar a importância do papel do professor-pesquisador nessas práticas, a partir do seu processo constante de análises de suas ações, apoiadas em diferentes teorias sobre línguas e ensino de línguas, o que lhe permitiu ressignificação das suas práticas.

Esta ressignificação foi possível a partir do momento em que o professorpesquisador se percebeu, juntamente com os seus alunos, como protagonista do processo de ensino-aprendizagem a partir da necessidade contínua de ação-reflexão-ação, propiciada pela agência docente e que permite a ele adequar as práticas de acordo com o contexto, com a realidade de ensino de modo contingencial e situado. 
Sua prática é também transformada a partir do momento em que o professor se percebe não como portador de uma verdade única (FOUCAULT, 2002), mas como sujeito educador que, juntamente com seus alunos, constrói sentidos (MONTE MÓR, 2018) entendendo a instabilidade das práticas educacionais, como práticas sociais, especialmente nos dias de hoje, em que se cobra do professor, como nos contextos das ações de internacionalização, os resultados em termos de "proficiência linguística", como se o professor fosse um mero treinador de habilidades específicas, e seus alunos recipientes vazios que recebem os conteúdos, ou seja, num processo de educação bancária, nos termos de Freire (1996).

Alinhados com a pesquisa de Sanches (2019) salientamos que, o professorpesquisador demonstrou, por meio de sua agência, a concepção de língua pertinente para o desenvolvimento de suas práticas de sala de aula, dada a liberdade que teve para atuar da forma mais adequada possível, dentro de suas possibilidades, e também a partir das necessidades e interesses dos alunos, valorizando os conhecimentos trazidos por eles por meio de uma prática de "respeito aos saberes dos educandos" (FREIRE, 1996, p. 33) que podem contribuir grandemente para a co-construção de outros saberes e, queremos crer, para a democratização do conhecimento em ações de internacionalização. Acreditamos, assim, que o espaço dado ao professor-pesquisador para exercer sua agência foi essencial para que ele pudesse fazer as mudanças necessárias e possíveis, a partir da compreensão dele sobre as características das práticas de sala de aula do seu contexto de ensino, ou seja, do PFI como ação de internacionalização. Da mesma forma foi importante dar espaço para os que alunos exercessem a sua agência na definição, com o professor, de como seriam as práticas para atender às suas necessidades específicas, adequadas ao nível em que se encontravam.

Além disso, gostaríamos de enfatizar a importância da formação permanente do professor para este processo de reflexão, ressignificação e mudança em suas práticas, que pode ser propiciada por cursos de extensão, pelo desenvolvimento de pesquisas em programas de pós-graduação, pela participação em grupos de estudos e de pesquisa, pela participação em grupos de discussão com outros professores nos contextos onde atua. 
Neste sentido, a formação permanente é fundamental para que o professor possa estar mais sensível aos contextos de suas práticas, e que possa ter subsídios teóricos e práticos para atuar com maior confiança e segurança, exercendo sua agência.

Quando elaboramos as ideias para a proposta do pôster para o FICLLA, principalmente em relação à proposta imagética do "liquidificador da internacionalização", um leitor cuidadoso desta imagem poderá perceber que não incluímos neste liquidificador dois ingredientes fundamentais para o preparo da "vitamina da internacionalização": o professor e os alunos. Sem esses ingredientes, a vitamina da internacionalização irá "desandar", como diriam as nossas avós.

Assim, por meio das reflexões aqui propostas, para que a "vitamina da internacionalização" não "desande", e que além disso seja saborosa, ou seja, que leve a resultados satisfatórios, é necessário adicionar esses ingredientes fundamentais, dando a eles a posição de protagonistas e, além disso, espaços de agência. Em outras palavras, as práticas dos cursos de língua inglesa do PFI - como ações de internacionalização - podem propiciar resultados bastante importantes, coerentes e adequados aos objetivos dos processos de internacionalização das universidades como políticas públicas que levam à democratização de conhecimentos, à "cooperação acadêmica, solidariedade institucional e liberdade de pensamento". Acreditamos que desta maneira os processos de internacionalização poderão contribuir para o desenvolvimento acadêmico e científico e, assim, trazer impactos nas esferas social, política e econômica do nosso país. Ou seja, se considerados esses aspectos, a vitamina da internacionalização será deliciosa!

\section{REFERÊNCIAS}

BRASIL. Ministério da Educação. Portaria n 1.466, de 18 de dezembro de 2012. Institui o programa Inglês sem Fronteiras. Diário Oficial da República Federativa do Brasil, Brasília, 19 de dezembro, 2012. Seção 1, p. 28. Disponível em: http://isf.mec.gov.br/images/pdf/ portaria_normativa_1466_2012.pdf. Acesso em: jan. 2019.

FOUCAULT, M. A ordem do discurso. $8^{\mathrm{a}}$ ed. São Paulo: Edições Loyola, 2002.

FREIRE, P. Pedagogia da Autonomia: Saberes necessários à prática educativa. $21^{\mathrm{a}}$ ed. Rio de Janeiro: Paz e Terra, 1996. 
HIBARINO, D. A. Vivências da agência docente nas aulas de língua inglesa no contexto do ProFIS-UNICAMP. Tese de Doutorado em Linguística Aplicada. Universidade Estadual de Campinas, 2018.

JORDÃO, C. M. O Ensino de Línguas Estrangeiras: de código a discurso. IN: VAZ BONI, V. Tendências contemporâneas no ensino de línguas. União da Vitória: Kaygangue, 2006, p.26-32.

JORDÃO, C. M. As lentes do discurso: letramento e criticidade no mundo digital. Trabalhos em Linguística Aplicada. Campinas, 46(1): 19-29, Jan./Jun. 2007.

JORDÃO, C. M. Abordagem comunicativa, pedagogia crítica e letramento crítico farinhas do mesmo saco? In: ROCHA, C.; MACIEL, R. Língua estrangeira e formação cidadã: por entre discursos e práticas.Campinas: Pontes, 2013. p. 69-90.

JORDÃO, C. M. No tabuleiro da baiana tem... letramento crítico? In: JESUS, D. M. de; CARBONIERE, D. (Orgs.). Práticas de Multiletramentos e Letramento Crítico: outros sentidos para a sala de aula de línguas.Campinas: Pontes, 2016, p. 41-53.

MENEZES DE SOUZA, L. M. T. Para uma redefinição de letramento crítico: conflito e produção de significação. In: MACIEL, R.F.; ARAÚJO, V.A. (Orgs.). Formação de Professores de Línguas: ampliando perspectivas. Jundiaí: Paco Editorial, 2011, p. 128-140.

MONTE MÓR, W. M. Critical Literacies, meaning making and new epistemological perspectives. Revista Electonica Matices em Lenguas Extranjeras, Bogotá, n. 2, 2008.

MONTE MÓR, W. M. Linguagem tecnológica e educação. Em busca de práticas para uma formação crítica. In: SIGNORINI, I.; FIAD, R. S. (Org.). Ensino de língua. Das reformas, das inquietações e dos desafios. Belo Horizonte: Editora UFMG, 2012. p. 171-190.

MONTE MÓR, W. M. Crítica e Letramentos críticos: reflexões preliminares. In: ROCHA, C. H; MACIEL, R. R. (Org.). Língua Estrangeira e Formação Cidadã: por entre discursos e práticas. Campinas: Pontes, 2013, p. 31-50.

MONTE MÓR, W. M. Letramentos críticos e expansão de perspectivas: diálogo sobre práticas. In: JORDÃO, C. M.; MARTINEZ, J. Z. e MONTE MÓR, W. Letramentos em prática na formação inicial de professores de inglês. Campinas: Pontes, 2018, p. 315-335.

ONO, F.; GOMES, J.. Internacionalização, letramento crítico e extensão: a experiência democrática do English Club na UFMS/CPTL. Revista Leitura, v. 2, no 61 - Maceió Jul./Dez. 2018, p. 76-91.

PORTAL CSF. Ciência sem Fronteiras. 2011. Disponível em: http://www.cienciasem fronteiras.gov.br/web/csf/o-programa. Acesso em: 05 mai. 2018. 


\section{Dossiê Especial FICLLA}

REVISTA X, Curitiba, volume 14, n.5,p. 181-202, 2019

SANCHES, G. J. O Programa Paraná fala Inglês: Uma autoetnografia sobre concepção de língua e material didático em sala de aula. Dissertação de Mestrado em Estudos Linguísticos. Universidade Federal do Paraná: Curitiba, 2019.

SANTOS, A. V.; GUIMARÃES-IOSIF, R. M. The internationalization of higher education in Brazil: a marketing policy. Journal of Contemporary Issues in Education, v. 8, no 1, 2013, p. 15-27. Disponível em: https://journals.library.ualberta.ca/jcie/index.php/JCIE/issue /view/1496. Acesso em: 16 set. 2019.

SETI. O Paraná fala Inglês: Site oficial. 2014. Disponível em: http://www.seti.pr.gov.br/ modules/conteudo/conteudo.php?conteudo=275. Acesso em: jan. 2019.

STREET, B. Social Literacies: Critical Approaches to Literacy in Development, Ethnography and Education. London: Longman, 1995.

STREET, B. The Implications of the 'New Literacy Studies' for Literacy Education. English in Education, Vol. 31, No. 3, 1997, p. 47-48.

STREET, B. Eventos de letramento e práticas de letramento: teoria e prática nos novos estudos de letramento. In: MAGALHÃES, I (org.). Discursos e práticas de letramento. Campinas: Mercado de Letras, 2012, p. 69-92. 